\title{
Os efeitos do conflito na Líbia: uma análise da atual crise migratória à luz do princípio da responsabilidade de proteger
}

\author{
The after-effects of the conflict in Libya: An analysis of the \\ current migratory crisis under the principle of responsibility to \\ protect
}

Deilton Ribeiro Brasil ${ }^{1}$

Julieth Laís do Carmo Matosinhos Resende ${ }^{2}$

\begin{abstract}
RESUMO:
O presente estudo tem como objetivo analisar o conflito na Líbia para estabelecer uma relação dos efeitos pós-conflito com os desafios no que concerne a atual crise migratória, tendo como paradigma o princípio da responsabilidade de proteger. Com esse propósito, o artigo será dividido em dois momentos. Primeiramente será realizada a delimitação e situação do objeto de estudo, analisando especificamente o conflito na Líbia e os efeitos pós-conflito ("conflito presente"). No segundo momento, será possível estabelecer a relação do princípio da responsabilidade de proteger com o atual cenário no país no que concerne a atual crise migratória, diante das graves violações dos direitos humanos. A escolha do tema justifica-se pela relevância do problema e pelos desafios no cenário internacional. Será utilizado como metodologia o levantamento de dados por meio de pesquisa bibliográfica e documental, adotando-se o método dedutivo.
\end{abstract}

\section{PALAVRAS-CHAVE:}

Conflito na Líbia - Pós-conflito - Crise migratória - Responsabilidade de proteger - Direitos humanos.

\footnotetext{
${ }^{1}$ Pesquisador visitante na University of Ljubljana e Università di Pisa (Eslovênia-Itália, 2017) com a supervisão do Prof. Dr. Ales Galic e da Profa. Dra. Maria Angela Zumpano. Pós-doutorado Direito na Università degli Studi di Messina (Itália, 2015-2016) com a supervisão do Prof. Dr. Mario Trimarchi. Pós-doutorado em Direito Ambiental no CENoR da Faculdade de de Direito da Universidade de Coimbra (Portugal, 2014-2015) com a supervisão da Prof ${ }^{a}$ Dra. Maria Alexandra Sousa Aragão. Pós-doutorado em Direito Constitucional junto ao Ius Gentium Conimbrigae/Centro de Direitos Humanos (IGC-CDH) da Faculdade de Direito da Universidade de Coimbra (Portugal, 2013-2014) com a supervisão do Prof. Dr. Jónatas Eduardo Mendes Machado. Doutorado em Direito pela Universidade Gama Filho do Rio de Janeiro-RJ (área de concentração em Estado e Direito: internacionalização e regulação) (2006-2010) com a orientação do Prof. Dr. Guilherme Calmon Nogueira da Gama.

${ }^{2}$ Mestre em Direito pela Universidade de Itaúna - UIT (2018). Graduada em Direito pela Faculdade de Direito de Conselheiro Lafaiete (2011)
} 


\begin{abstract}
:
The present study aims to analyze the conflict in Libya to establish a relationship of the postconflict effects with the challenges regarding the current migratory crisis, having as a paradigm the principle of the liability to protect. For this purpose, the article will be divided into two moments. Firstly, the delimitation and situation of the object of study will be carried out, analyzing specifically the conflict in Libya and the post-conflict effects ("present conflict"). In the second moment, it will be possible to establish the relation of the principle of liability to protect with the current scenario in the country regarding the current migratory crisis, in the face of serious violations of human rights. The choice of the issue is justified by the relevance of the problem and the challenges in the international scenario. It will be used as methodology the data collection through bibliographical and documentary research, adopting the deductive method.
\end{abstract}

\title{
KEYWORDS:
}

Conflict in Libya - Post-conflict - Migratory crisis - Responsibility to protect - Human rights. 


\section{INTRODUÇÃO}

O caso da Líbia, dentre os levantes da primavera árabe, é um conflito que requer atenção no que concerne aos efeitos deixados no país após a intervenção humanitária sob o escopo do princípio da responsabilidade de proteger. Em virtude do prolongado conflito armado na Líbia, desde a queda do ditador Muammar Kadafi em 2011 e a contestação dos resultados das eleições de 2014, o país tem enfrentado inúmeros desafios. Nesse sentido, o presente artigo tem como objetivo analisar a atual crise migratória instalada no país e a relação entre o conflito interno e a aplicação do princípio da responsabilidade de proteger.

Os confrontos internos entre facções rivais e diferentes entidades armadas, além da atual crise humanitária fruto da instabilidade política diante do vácuo de governança no país tem gerado pressões prolongadas em um cenário de instabilidade, fragmentação, crise econômica e diversas violações de direitos humanos, o que tem contribuído para o aumento do fluxo migratório e da atual crise migratória no país.

Dentro desse contexto, o presente artigo pretende analisar os efeitos resultantes do conflito interno na Líbia diante da situação crítica instalada no país, tendo como principal objetivo verificar a relação com a atual crise migratória e aplicação da responsabilidade de proteger. Com esse intuito o presente artigo pretende analisar desde a formação do conflito interno, a resistência do ditador Qaddafi, as interferências políticas de instituições e países estrangeiros no conflito e com relação aos aspectos específicos do fluxo migratória e desafios no país no que concerne as violações aos direitos humanos.

Para isso, o artigo será dividido em dois momentos. Primeiramente será realizada a delimitação e situação do objeto de estudo, analisando especificamente o conflito na Líbia e a aplicação do Princípio da Responsabilidade de Proteger. No segundo momento, serão verificados os efeitos pós-conflito, estabelecendo uma relação com o atual cenário no país no que concerne a atual crise migratória. Com isso, será possível analisar o tema proposto à luz da responsabilidade de proteger, tendo em vista as violações dos direitos humanos.

A metodologia será descritiva e analítica, que permitirá uma abordagem de conceitos importante para o desenvolvimento da temática. Será realizada uma pesquisa bibliográfica e documental, com enfoque em leituras doutrinárias e outros documentos que digam respeito ao 
assunto abordado. Dessa forma, o levantamento possibilitará bases teóricas na construção da pesquisa e na descoberta de conceitos que contribuirão para uma conclusão efetiva do presente estudo. O método utilizado para o desenvolvimento da pesquisa é o dedutivo.

A escolha do tema justifica-se pela relevância jurídica e social do problema e pelos desafios no cenário internacional. A problemática estabelecida no presente artigo acrescentase ao amplo conjunto de desafios que tornam o tema crise migratória carecidos de muitas reflexões. Trata-se, portanto, de um trabalho que deve interessar todos aqueles que se preocupam com temas que envolvem conflitos armados e responsabilidade de proteger, mas sobretudo proteção aos direitos humanos.

\section{DELIMITAÇÃO E SITUAÇÃO DO OBJETO DE ESTUDO: O CONFLITO NA LÍBIA E O PRINCÍPIO DA RESPONSABILIDADE DE PROTEGER}

A Líbia está situado norte da África. Inicialmente, seu território se dividia em três províncias controladas por diferentes Estados. Com a independência do país em 1952, a monarquia instituída, tinha como principal objetivo unir os povos, no entanto já no ano de 1969, um grupo de oficias nacionalistas, liderado pelo Muammar Qaddafi, tomou o controle do país e deu um golpe de Estado, derrubando o Rei Idris.

A partir de então, o país passa a ser liderado pelo Coronel Muammar Qaddafi que ficou no poder por 42 anos, período que ficou conhecido como a "Era Qaddafi|". Como principais atitudes para descrever o Governo, pode-se destacar a monopolização do controle das Forças Armadas, instrumentos de comunicação e outras instituições governamentais (CIA WORLD FACTBOOK, 2011)

Muammar Qaddafi era rotulado como extravagante e enigmático, suas atitudes diferentes surpreendiam o povo líbio e sociedade internacional. Fazia questão de mostrar e preservar suas tradições, nas viagens como chefe de Estado usava roupas típicas, coloridas e invés de se hospedar em hotel, armava uma tenda. Sua personalidade sempre foi um mistério, as opiniões se dividiam: para os inimigos era um considerado um Ditador e já para os seus seguidores era considerado um líder, chamado de Coronel. Muammar Qaddafi se definia como o "Rei dos Reis", o que já demostrava o seu narcisismo patológico, a necessidade de estar em evidência e de ser o todo poderoso. E quando contrariado se tornava uma bomba-relógio. 
A trajetória política, o poder e a relação de Qaddafi com os outros países sempre esteve relacionada com os poços de petróleo da Líbia. O ditador era contra as explorações das

reservas de seu país por empresas estrangeiras, então optou por nacionalizar o petróleo e com isso ganhou alguns inimigos, como os EUA e Europa.

Nas décadas de 80 e 90 Qaddafi patrocínio atentados terroristas e também foi vítima de tentativas de assassinato. Somente no ano de 2005 Qaddafi permitiu o retorno de empresas americanas para explorar gás e petróleo no país. O então presidente dos EUA, George W. Bush, retirou a Líbia do lista de países terroristas. Mas com o tempo, os serviços de inteligência americano e britânico descobriram que a Líbia tinha novos planos para o petróleo do país, o que não agradado as grandes potências. Por coincidência, nesse mesmo período surgia a revolta no mundo árabe e os líbios tomaram coragem para enfrentar o ditador, que agora já tinha fortes inimigos.

No final do ano de 2010 formou-se uma onda de protestos em todo Oriente Médio. O levante da denominada "Primavera Árabe", como ficou conhecido as manifestações contra corrupção e maus tratos ganhou força na região. O primeiro protesto ocorreu contra o governo da Tunísia, quando um jovem incendiou o próprio corpo. O caso ganhou grande repercussão e após esse acontecimento foram difundidos outras inúmeras manifestações em vários países. A Líbia não foi exceção a essa regra.

\subsection{Algumas considerações sobre o conflito na Líbia - o conflito presente}

Na Líbia os protestos se iniciaram no Leste do país, região em que o Governo possuía menor apoio. No entanto, o estopim ocorreu com a prisão de um advogado defensor de causas de famílias vítimas de um suposto ataque em Trípoli, nos anos 90, realizado pelo governo. Assim, iniciou-se uma onda de protestos no país que passou a ser dividido entre as cidades controladas pelos rebeldes e aquelas controladas pelo governo ditatorial.

Diante das inúmeras manifestações o ditador instaurou no país uma verdadeira guerra civil para se manter no poder, com bombardeios aos nacionais por parte do próprio governo. Em um discurso oficial, Qaddafi se pronunciou para que seus aliados ajudassem a "limpar o país" até que os rebeldes se rendessem. Tais ações e reações foram consideradas pelo países ocidentais como crime contra humanidade, pois esses ataques se destinavam a população 
Líbia, envolvendo assassinatos, privações, aprisionamentos, enfim graves violações aos direitos humanos.

Diante dessa situação, o Conselho de Segurança da ONU em fevereiro de 2011 aprovou a Resolução $n^{\circ}$ 1970, que invocava a responsabilidade do governo líbio de sua responsabilidade de proteger sua população. Nesse mesmo momento foram estabelecidas inúmeras sanções ao país, como embargos de armas e congelamento de bens. No entanto, o governo líbio desconsiderou tais sanções e continuou perpetrando inúmeras e severas violações aos direitos humanos do povo líbio.

Dentro desse contexto a sociedade internacional invocou o princípio da Responsabilidade de Proteger como justificativa para uma intervenção na Líbia com o objetivo de proteção dos direitos humanos. Isso porque, quando o Governo líbio se abdicou de sua responsabilidade primária de proteger sua população, de acordo com o princípio da responsabilidade de proteger, essa responsabilidade passou a ser de competência da comunidade internacional.

Dessa forma, o Conselho de Segurança da ONU, em 17 de março de 2011, aprovou uma nova resolução no 1973, que instigava os Estados-membros a tomarem todas as medidas cabíveis no sentido de proteção a população Líbia. E nesse mesmo ato estabeleceu-se uma zona de exclusão aérea. Com essa resolução, o Conselho de Segurança autorizou o uso da força com a finalidade de proteção aos direitos humanos sem o consentimento do país envolvido, tendo como justificativa o princípio da Responsabilidade de Proteger.

As operações feitas pela Organização do Tratado do Atlântico Norte (OTAN), são alguns dos casos em que a ONU passa o comando das missões para organizações regionais, como pode ser observado na Líbia.Com a intervenção humanitária, liderada pela OTAN e com o forte apoio dos países do ocidente, o Governo de Qaddafi perde força e em 20 de outubro de 2016 o ditador é assassinato por rebeldes.

Após a derrubado do Governo de Qaddafi, assume o poder do país o Conselho Nacional de Transição (2011-2012). As primeiras eleições ocorreram em 2012 quando o Conselho Geral Nacional substitui o Conselho Nacional de Transição. No ano de 2014 ocorre as eleições para Câmara dos Representantes da Líbia (também denominado Conselho dos Deputados). Os candidatados derrotados não concordam com o resultado e criam o Novo Congresso, em oposição à Câmara eleita. Assim, o Governo se divide e a Líbia continua 
inserida no mesmo cenário de instabilidades. A ONU na tentativa de estabelecer uma acordo na disputa pelo poder cria o Governo da União Nacional.

A disputa pelo poder se concentra nas mãos de diferentes pessoas e em diferentes regiões do país. Trípoli, na região oeste, é a base do Governo de Acordo nacional, conhecido pela sigla GNA. Essa entidade foi formada com o apoio da ONU no início de 2016. Fayes alSarraj é o primeiro ministro. Boa Parte da Comunidade internacional, incluindo os EUA, apoiam esta força, assim como diversas milícias.

Na região leste do país, em Tobruk, o Exército Nacional Líbio é liderado pelo general Khalifa Haftar, poder baseado na promessa de combater o terrorismo com vigor. Haftar havia servido com Gaddafi, mas em seguida, participou de um complô para derrubá-lo e participou da insurgência de 2011. O governo de Tobruk controla regiões de importante produção de petróleo.

A presença do Estado Islâmico, facção radical, foi ampliada pelos militares estrangeiros que estavam na Líbia para a derrubada de Gaddafi. A organização era liderada pelo iraquiano Abu Nabil, morto em um ataque aéreo americano em 2015. Há dúvidas sobre quem é a cabeça da milícia hoje, possivelmente um homem chamado Abdul Qadr al-Nadji. Ansar al- Sharia é uma organização terrorista formada em 2012 pela mescla de diversas milícias de menor porte. Há laços com a rede Al Qaeda- negados pelo próprio grupo - e diversos de seus membros viajaram à Síria, ao Iraque e ao Mali. Sua base é Benghazi.

Diante dessa instabilidade na política interna na Líbia, foi promovido em julho de 2017 um encontro em Paris, que contou com a presença do comandante baseado no Leste, Khalifa Haftar e o primeiro-ministro de Trípoli, Fayez Seraj, e os líderes das assembleias parlamentares rivais, como o objetivo de acordo sobre os com os princípios gerais para acabar com a crise líbia e permitir a realização de eleições.

Assim, os líderes das principais facções rivais que disputam o poder político assinaram uma declaração no compromisso de organizar eleições em dezembro deste ano. De acordo com o comunicado, as bases institucionais devem ser acertadas até 16 de setembro e as eleições ocorreriam inicialmente no dia 10 de dezembro. $\mathrm{O}$ acordo prevê a aceitação por todas as partes das propostas da ONU, tanto para a elaboração de uma base constitucional que emoldure o processo eleitoral como para a realização do pleito. A ONU fornecerá a ajuda necessária à Líbia para que essas eleições possam se desenvolver nas melhores condições. $\mathrm{O}$ secretário-geral da ONU, António Guterres, elogiou o acordo alcançado por líderes rivais da 
Líbia para a realização de eleições, como um "significativo e bem-vindo passo adiante" para a transição política no país (ONU, 2018)

Diante do vácuo na governança do país desde a morte de Qaddafi a Líbia tem passado, nos últimos sete anos, por uma situação crítica, segundo a ONU. Dentro desse cenário de instabilidades e graves violações de direitos humanos, pode-se destacar a atual crise migratória no país como um dos principias desafios para a sociedade internacional e para o Governo que assumirá o país com as eleições que ocorrerão ainda esse ano. A estabilidade política na Líbia tem sido a esperança em busca de melhores condições de vida de toda a população do país, incluindo refugiados e migrantes.

Feitas essas considerações sobre o contexto do conflito e sobre a intervenção na Líbia para compreender melhor a proposta do presente estudo cabe nesse momento adentrar na análise do princípio da responsabilidade de proteger e suas principais características.

\subsection{Noções gerais sobre o princípio da responsabilidade de proteger}

A existência de crimes de atrocidade em massa no cenário internacional e a ausência de reação da sociedade internacional em muitos casos, diante dessas graves violações de direitos humanos perpetradas nos últimos anos, fez com que as Nações Unidas se despertasse pelo interesse de estabelecer medidas para remediá-los e principalmente evitá-los, na busca pela efetividade na proteção de direitos humanos.

Os diálogos propostos nos fóruns multilaterais sobre o tema foram os principais responsáveis em estabelecer uma nova abordagem da soberania versus proteção do indivíduo, em que os Estados assumam suas responsabilidades na proteção de seus cidadãos. A sociedade internacional passou a inadmitir graves violações aos direitos humanos sob a justificativa de soberania estatal (ICISS, 2001).

Assim, dentro desse contexto, surge o Princípio da Responsabilidade de Proteger que preceitua o compromisso da sociedade internacional de proteger as nações diante de crimes contra a humanidade, casos de genocídios, crimes de guerra e limpezas étnicas. Acompanhando a evolução e desenvolvimento histórico do conceito de soberania estatal e diante desse princípio o conceito de soberania estatal passa a ser reformulado no sentido de proteção dos direitos humanos e não mais como um álibi de governos ditadores. 
O princípio da Responsabilidade de Proteger (R2P) surgiu no ano de 2011 através da International Commission on Intervention and State Sovereignty - ICISS (Comissão Internacional sobre Intervenção e Soberania do Estado) que estabeleceu um nível abrangente a legitimidade das intervenções humanitárias tendo como paradigma a responsabilidade de proteger. Tal comissão era composta por importantes teóricos, como Mohamed Sahnoun e Gareth Evans.

O princípio da responsabilidade de proteger passou a ser endossado pelos ativistas e depois de uma década de sua criação, foi adotado em 2005 pelos membros das Nações Unidas. Tem-se, uma visão da importância do princípio como justificativa em intervenções humanitárias, como por exemplo no caso da Líbia em 2011. No entanto, apesar da sua rápida difusão e do reconhecimento de sua importância, há ainda muitos desafios no que concerne a sua aplicabilidade de forma coerente ao sentido de sua criação, qual seja, proteção dos direitos humanos.

Tais críticas surgem pelo fato e muitos argumentos de que o princípio muitas vezes é utilizado como justificativa para outros interesses, como econômicos e políticos. Sendo utilizado, portanto, com objetivos em interesses obscuros que não se coadunam com a proteção humanitária, que deveria ser o objetivo principal na aplicação do referido princípio.

É importante destacar que o princípio da responsabilidade de proteger está intimamente ligado à responsabilidade dos Estados de protegerem seus próprios cidadãos contra genocídios, crimes de guerra, crimes contra a humanidade e limpezas étnicas. No entanto, na hipótese em que esses mesmos Estados encontram-se incapacitados ou indispostos a realizarem tal proteção, torna-se responsabilidade residual da comunidade internacional darlhes assistência, ou empregar medidas que os coajam a proteger a própria população (ICISS, 2001).

O desenvolvimento e conquistas dos direitos humanos e do direito humanitário têm uma forte relação com a rápida difusão do princípio da responsabilidade no sentido do diálogo entre soberania estatal e proteção do indivíduo. É importante destacar que tal princípio não tem fundamento na rejeição da soberania, mas numa reformulação em que a ideia de soberania deve ser compreendida como responsabilidade primordial do Estado na proteção de seu povo (JUBILUT, 2008). Portanto, a comunidade internacional representa, então, um papel secundário de auxílio aos Estados na proteção dos indivíduos contra violações massivas 
dos direitos humanos, devendo garantir esses direitos quando os Estados se revelam incapazes ou indispostos a fazê-lo (ONU, 2005).

A Cúpula Mundial das Nações Unidas de 2005 definiu expressamente os casos em que o princípio deve ser aplicado crimes contra a humanidade, crimes de guerra, limpeza étnica e genocídio (que estão ocorrendo ou na iminência de ocorrer) (AGNU, 2005). De acordo com o entendimento da ONU, crime contra a humanidade pode ser definido como qualquer ação generalizada ou ataque direcionado a uma determinada população que possuir relação com: assassinatos; extermínio; escravidão; deportação ou transferência forçada de população; aprisionamento ou outras privações severas de liberdades físicas que violem leis fundamentais da lei internacional; tortura; estupro; e escravidão sexual (ONU,2005).

De acordo com as Convenções de Genebra crimes de guerra podem ser definidos como assassinato voluntário; tortura ou tratamento desumano; e o uso de reféns e apropriação de propriedades de forma não justificada pela necessidade militar ou pela lei (CONVENÇÃO DE GENEBRA, 1949). Deve-se lembrar que quando se fala em crime de guerra, deve-se ter em mente que referido crime pode ser cometido apenas por um indivíduo, que pode ser assim responsabilizado pelas ações de um país ou pelos soldados daquela nação (MAZZUOLI, 2016).

Segundo o artigo II da Convenção sobre a Prevenção e Punição do Genocídio de 1948, estabelece que para se configurar o crime de genocídio é preciso do elemento mental, que consiste no objetivo de destruir, total ou parcialmente, um grupo nacional, étnico ou religioso, e elemento físico, que consiste em matar indivíduos de determinado grupo, causarlhes danos físicos ou mentais e afetar deliberadamente suas condições de vida de forma destrutiva, implementar medidas que impeçam o nascimento de novos indivíduos de um grupo e a transferência forçada de crianças de um grupo para outro.

O conceito de limpeza étnica deve ser associado tanto a um crime de guerra quanto a um crime contra a humanidade, que pode ser definido, em linhas gerias, como o ato de expulsão de um grupo "indesejado" de determinado local.

Do princípio da Responsabilidade de Proteger pode-se dizer que há três principais responsabilidades: prevenir, reagir e reconstruir. Com esses elementos, percebe-se que o princípio se diferencia de uma mera intervenção humanitária (ICISS, 2001). A responsabilidade de proteger configura-se em um conjunto de atos entre o Estado e a sociedade internacional, que envolve inicialmente a prevenção até a reconstrução. Isso não 
significa que tais atos devem ser desencadeados de forma continua, tendo em vista, por exemplo, que os primeiros atos no combate às crises humanitárias não levarão, inevitavelmente, a uma ação coercitiva militar.

De acordo com a principal função da responsabilidade de proteger, a fase de prevenção é a dimensão que deve ser considerada como prioridade, ou seja, que requer maior dedicação por parte do Estado e toda a sociedade internacional. Somente depois de perpetradas medidas possíveis para prevenir o conflito e violações de direitos humanos é que se pode pensar na dimensão de reagir. A aplicação dessa dimensão, portanto, envolve o desenvolvimento de todos os mecanismos efetivos de prevenção para tentar impedir uma ação coercitiva.

A responsabilidade de reagir pode ser perpetrada quando a prevenção falha. É importante lembrar que tal responsabilidade cabe ainda ao próprio Estado, mas diante de sua incapacidade ou quando o próprio governo é o agente causador das atrocidades essa responsabilidade passa para a comunidade internacional. Cabe destacar que o Conselho de Segurança das Nações Unidas, sob o artigo 24 da Carta da ONU, tem a competência de manter a paz e segurança internacionais, o que faria dele o órgão considerado mais legítimo para decisões ligadas à R2P.

A responsabilidade de reconstruir deve ocorrer no momento posterior à intervenção militar. De acordo com o relatório da ICISS, trata-se de um "comprometimento genuíno com o auxílio à reconstrução de uma paz duradoura, a promoção de boa governança e o desenvolvimento sustentável” (ICISS, 2002). Essa dimensão da Responsabilidade de Proteger é um procedimento que tem como intuito manter a paz que foi conquista com a intervenção e trabalhar para evitar novos conflitos.

Assim, de acordo com o relatório da ICSS nessa dimensão é preciso estabelecer inúmeros esforços no sentido de auxiliar a reconstrução e restauração da ordem no país em diversas áreas, como segurança, política, social e econômica, mas sobretudo na paz e na proteção dos direitos humanos.

\section{CRISE MIGRATÓRIA NA LÍBIA E O PRINCÍPIO DA RESPONSABILIDADE DE PROTEGER}


Com a morte de Qaddafi e o fim da ditadura de 42 anos, a esperança do povo líbio, naquele momento, era instaurar a democracia no país. Ocorre, que não demorou muito tempo, para perceberem que esse sonho estava bem longe de ser atingido. Quando parecia o fim de um conflito, a Líbia vira palco de novas disputas entre diferentes poderes e diversas milícias, fundamentados em interesses políticos, religiosos e econômicos.

Com isso, é denominada uma nova fase do conflito na Líbia, ou melhor, a continuidade do conflito, agora com outros atores, mas, talvez, possa-se afirmar com os mesmos objetivos, qual seja, a disputa pelo poder. Essa nova fase do conflito na Líbia, também denominada "conflito presente", trouxe para o caso Líbio novos desafios. Um país que já estava fracassado devido ao longo período de conflito interno até a derrubada do Governo do ditador e que se vê mergulhado no mesmo cenário de destruição, instabilidades e novas violações de direitos humanos.

Os conflitos armados estão entre os principais motivos da atual crise migratória mundial. Nesse sentido, a sociedade internacional tem enfrentado grandes desafios na busca pela proteção efetiva dos direitos humanos dessas categorias de pessoas que se movimentam pelo mundo em busca de paz e proteção mínima dos direitos humanos.

Segundo dados atuais, há aproximadamente 65,3 milhões de pessoas em situação de deslocamento, entre elas mais de 21,3 milhões são Refugiados. De acordo com a Organização Internacional para Migrações há aproximadamente 244 milhões de migrantes pelo mundo. E segundo a ONU a tendência é que o número de refugiados e migrantes ganhe mais proporções nos próximos anos (ONU, 2017).

Dentro desse contexto é importante compreender a diferença entre refugiados e migrantes. É muito comum a confusão entre tais conceitos o que pode gerar algumas dificuldades na proteção adequada, principalmente para os refugiados que possui um regime de tratamento específico. Diante disso, o Alto Comissariado das Nações Unidas para Refugiados (ACNUR), conhecido como Agência da ONU para Refugiados, estabelece sobre a necessidade em se referir a refugiados e migrantes separadamente, para que assim se matenha as diferenças entre eles, principalmente acerca das causas e características dos movimentos de refúgio, além de manter evidentes as obrigações específicas voltadas aos refugiados nos termos do direito internacional.

O Direito Internacional dos Refugiados é o regime legal específico em proteção aos direitos dos refugiados, e é regulamentado em pela Convenção Relativa ao Estatuto dos 
Refugiados de 1951 e pelo seu Protocolo de 1967. Dentro desse contexto, pode-se destacar como alicerce desse regime de proteção o princípio de non-refoulement (que significa não devolução), estabelecendo que "refugiados não podem ser expulsos ou devolvidos a situações onde suas vidas ou liberdade possam estar sob ameaça". Cabe destacar, ainda, que há regulamentações regionais como a Convenção Relativa aos Aspectos Específicos dos Refugiados Africanos 1969 e a Declaração de Cartagena sobre Refugiados de 1984. Nas lições de Valério de Oliveira Mazzuoli, conjugando a Convenção de 1951 e o Protocolo de 1967, consideram-se refugiados:

Qualquer pessoa que temendo ser perseguida por motivos de raça, religião, nacionalidade, grupo social ou opiniões políticas, se encontram fora do país de sua nacionalidade e que não pode ou, em virtude desse temor, não quer valer-se da proteção desse país, ou que, se não tem nacionalidade e se encontra fora do país no qual tinha sua residência habitual, não pode ou, devido ao referido temor, não quer voltar a ele. (MAZZUOLI, 2016, p. 350)

Com relação aos direitos dos Migrantes, inicialmente, é importante destacar que não há um tratado internacional específico sobre a matéria, existindo apenas alguns documentos que tratam do tema de migrantes sobre diferentes viés, como algumas Convenções da Organização Internacional do Trabalho (OIT). Dessa forma os migrantes são protegidos em âmbito internacional pelo direito internacional dos direitos humanos, essa proteção deriva de sua dignidade fundamental enquanto seres humanos, pois todas as pessoas, independente do seu status, devem ser protegidas.

A migração deve ser compreendida como processo voluntário, em que as pessoas cruzam uma fonteria em busca de melhores condições de vida, por motivos diversos, como oportunidade de emprego, melhoria na educação, fome ou extrema pobreza. Por isso é importante diferenciar refugiados e migrantes, pois possuem diferenças que são de extrema relevância no tratamento legal.

No entanto, apesar de não existir no cenário internacional uma proteçao específica aos migrantes, é importante destacar que tais pessoas também sofrem graves violações de direitos humanos, como discriminações, prisão arbitrária, exploração de trabalho, tráfico de pessoas, menores separados ou desacompanhados, dentre outras. Dessa forma, é preciso que a sociedade internacional garanta a proteção efetiva dos direitos humanos dos migrantes, pois há ainda muito que se desenvolver sobre essa questão. 
O desequilíbrio econômico internacional, a pobreza, o subdesenvolvimento, a falta de oportunidades, a má governança, fatores ambientais, ausência de paz, segurança e à falta de gozo dos direitos humanos estão entre os motivos que levam, a cada dia mais, o crescente fenômeno da migração. Os deslocamentos forçados e a migração irregular de pessoas nos grandes movimentos são problemas complexos, somado ao grande número de mortes de refugiados e migrantes no Mar Mediterrâneo

Nesse sentido, a sociedade internacional tem-se preocupado cada vez mais em desenvolver medidas capazes de atender à essa nova demanda, em que se possa oferecer condições dignas de subsistência e integração de forma efetiva na proteção dos direitos humanos no contexto atual. Tendo em vista esse objetivo, cabe destacar que a Assembleia Geral da ONU aprovou a Declaração de Nova York sobre Refugiados e Migrantes.

A Reunião de Alto Nível sobre Respostas aos Grandes Movimentos de Refugiados e Migrantes foi realizada no dia 19 de setembro de 2016, na sede da ONU em Nova York, contando com a presença de chefes de Estados e Governos e altos representantes, que aprovaram um documento político que ficou conhecido como Declaração de Nova York sobre Refugiados e Migrantes, como o propósito de assumirem inúmeros compromissos com relação ao tema, mas principalmente da elaboração e aprovação dos Pactos Mundiais para lidar com a atual crise migratória mundial.

Feitas essas considerações sobre a proteção jurídica no cenário internacional no que concerne aos refugiados e migrantes, que são de extrema relevância para se compreender a proposta do presente estudo, é importante adentrar especificamente na análise da crise migratória instalada especificamente na Líbia.

Inicialmente é importante destacar que antes mesmo do conflito na Líbia, o país já era centro de recebimento de refugiados e migrantes de todas as região norte e central da África, em virtude de sua localização, considerado assim um dos principais trajetos de deslocamentos daqueles que fugiam de conflitos internos em outros países.

Com a instabilidade no país durante e após o conflito de 2011, a Líbia passou a ser rota principal, tendo em vista a ausência de segurança nas fronteiras por causa da dos conflitos internos no país. Além disso, os próprios líbios se juntavam a esse conjunto de pessoas que se deslocavam rumo a outros países para fugir dos conflitos internos agora em seu território. 
Com esse cenário de instabilidade na segurança das fronteiras no país, quer durante o conflito ou após este, que também se tornou outro momento de instabilidades no país em virtude do vácuo na governança, a Líbia passou a ser destino também de muitos traficantes que aproveitam da situação do país para explorar, escravizar e cometer inúmeras outras graves violações de direitos humanos contra os refugiados e migrantes, pessoas em situação de alta vulnerabilidade.

Os desafios na Líbia, em virtude do conflito armado de 2011 e seus efeitos, ainda se fazem presente no país, que tem passado nos últimos anos por instabilidade e fragilidades em diversas áreas, como na política, segurança e econômica. Ocorre que, dentre tais desafios a atual crise migratória tem despertado a preocupação da sociedade internacional na proteção dos direitos humanos diante das graves violações que estão ocorrendo no país há anos e agora, recentemente tem intensificado cada vez mais, com os casos de leilões de refugiados e migrantes.

A situação atual na Líbia pode ser caracterizada como crítica diante das instabilidades políticas, sociais e econômicas, disputas religiosas e pelo poder por diversas milícias, grupos armados e terroristas, contrabando de petróleo, tráfico de armas e drogas, tráfico de migrantes escravizados e inúmeras violações de direitos humanos. Tudo isso tem contribuído, significativamente para atual crise migratória instalada no país e pelos diversos desafios na proteção dos direitos humanos no território líbio.

O mundo tem acompanhado relatos e imagens assustadoras de refugiados e migrantes em situação desumana na Líbia. De acordo com informações da Organização Médicos Sem Fronteiras alguns refugiados e migrantes estão em centros governamentais em condições cada vez piores, sem água e comida suficientes, mas a maioria deles estão nas mãos de redes de contrabando, que utilizam de tortura para extorquir dinheiro das famílias. (MSF, 2018)

Durante sua estadia na Líbia, a maioria dessas pessoas são roubadas, mantidas sob controle de redes criminosas, abusadas, presas, espancadas, torturadas e, algumas delas, mortas

Apesar de ações humanitárias realizadas por organizações, como a ACNUR e MSF, muito ainda tem que ser feito pela sociedade internacional como um todo, tendo em vista a realidade dessas pessoas que sofrem diariamente graves violações dos seus direitos humanos. 
Os refugiados e migrantes no território Líbio fazem parte do que se pode denominar fluxos mistos. Alguns vieram trabalhar na Líbia, antes dos conflitos internos nos países, quando o país era referência econômica na região. Outros estão no país detidos ou trabalhando em condições análogas ao trabalho escravo para arrecadar dinheiro e fazer a travessia no mar Mediterrâneo. E há ainda aqueles líbios, que devido aos conflitos no território, se movimentam pelo país para fugir do conflito na Líbia.

Os refugiados e migrantes descrevem a jornada pelo deserto líbio e as estadias nos em centros controlados por redes criminosas como desafios dolorosos nessas travessias. Somado a tudo, são vitoriosos os que vivem a tantas crueldades. No ano 2016, cerca de 5 mil pessoas se afogaram no Mediterrâneo e em 2017, estima-se que o número tenha sido ainda maior. (MSF, 2018)

As Nações Unidas, através da ACNUR tem implementado medidas para ajudar a amenizar a situação no território líbio. Muitos indivíduos estão sendo reassentamento em outros países e o objetivo é evacuar outros milhares de refugiados até o final deste ano (ONU, 2018). A ONU tem solicitado que o governo líbio tome medidas urgentes para acabar com o comércio de pessoas escravizadas no país. É um absurdo, em pleno século XXI, ver as imagens que mostram refugiados e migrantes sendo leiloados como mercadorias, cenas que retorna a um capítulo sombrio que deveria ser esquecido na história da humanidade, quando milhões de africanos foram arrancados, escravizados, traficados e leiloados.

Dentro desse cenário, o Conselho de Segurança das Nações Unidas condenou o tráfico de migrantes escravizados na Líbia, qualificando o acontecimento como um "abuso hediondo dos direitos humanos que se constitui como crime contra a humanidade", solicitando que autoridades libanesas e Estados-membros cumpram de maneira urgente com suas obrigações sob o direito internacional (ONU, 2018). O que se tem percebido é que a sociedade internacional tem demonstrado preocupação com a realidade do país, principalmente com relação aos casos de tráfico de pessoas, diante dos recentes relatos de migrantes e refugiados sendo vendidos como escravos na Líbia.

E a pergunta que fica: quantas pessoas ainda morreram na busca pela proteção de seus direitos humanos? Essa é a triste realidade da crise migratória na Líbia, que é resultado dos conflitos armados no país e em países vizinhos. É preciso que a sociedade internacional, assuma suas responsabilidades e interfiram nesses países, seja através da intervenção 
humanitária ou pelo princípio da responsabilidade de proteger, mas sempre no sentido de proteção e não com base em outros interesses.

\subsection{Análise-crítica do princípio da responsabilidade de proteger no caso da Líbia}

É importante notar que princípio da responsabilidade de proteger não possui aceitação universal, mas tem sido amplamente aceito pela maioria da doutrina e ganhando espaço crescente nas discussões sobre Direitos Humanos e intervenções humanitárias. Como foi apresentado ao longo do artigo, o princípio da responsabilidade de proteger apresentou um rápido desenvolvimento desde sua criação oficial pela ICISS em 2001, até seu uso como justificativa à intervenção na Líbia, em 2011. De acordo com a maioria da doutrina, foi o caso Líbio o marco de aplicação do princípio da R2P, como justificativa pelo Conselho de Segurança na intervenção humanitária, sendo, portanto, apesar de críticas, o momento de consolidação de tal princípio. É inegável, porém que seu estabelecimento no cenário internacional ainda encontra muitos desafios.

A principal crítica com relação a aplicação da Responsabilidade de Proteger é pautada na seletividade e em conveniências políticas e econômicas dos países do ocidente na intervenção na Líbia. Muito se questionou, o porquê da aplicação do princípio no país, quando ao mesmo tempo, existiam outros países que passam por inúmeros conflitos internos e inúmeras violações de direitos humanos que justificariam uma interferência sob a mesma justificativa, como por exemplo, o caso da Síria.

Há certa dificuldade de mobilizar que um Estado se envolva numa operação com o intuito de proteção aos direitos humanos em outro território, na prática isso tem uma relação com a vontade política de cada Estado e não no cumprimento dos compromissos internacionais. E por isso a crítica muito frequente ao princípio da responsabilidade de proteger se volta para esse contexto, na afirmação de que, não importando as considerações morais inerentes ao princípio, sua implementação nunca é livre dos interesses dos Estados que intervêm. Assim, alguns críticos ao princípio argumentam que sobre a sua aplicação para justificar qualquer interesse de um país poderoso, sendo, assim um mecanismo de imposição das grandes potências sobre pais menos desenvolvidos.

Como salientado no presente artigo, interesses geopolíticos na Líbia por causa das reservas de petróleo tem forte relação com interferência dos países do ocidente, tendo em vista que o Governo Líbio tinha broqueado o acesso de outros países nas reservas de petróleo 
do país. Outra crítica significativa, que pode ser destacada, é pautada na ausência de dimensão de reconstrução, o que acaba deixando a responsabilidade de proteger sem efeito prático no caso do conflito da Líbia, isso porque após o conflito de 2011 não se realizou todas as medidas necessárias de reconstrução, no sentido de pacificar as disputas e estabilizar a situação econômica, política e social no país. O que levou muitos a comparar o princípio com a uma mera intervenção humanitária, com apenas propósitos militares.

Apesar das críticas, a intervenção na Líbia é considerada pela maioria da doutrina a principal referência na aplicação de tal princípio, representando grande avanço nas ações humanitárias, no sentido de proteção dos direitos humanos e com a participação e aceitação de diversos atores internacionais. A intervenção na Líbia, sob o escopo do princípio representa o primeiro passo para que se possa chegar à sua efetiva implementação e proteção dos direitos humanos. Sabe-se, entretanto, que a R2P possui muitos desafios a serem vencidos para que seja possível a sua implementação apropriada nas práticas internacionais, livre de outros interesses.

De fato, há o problema da falta de consenso sobre a sua aplicabilidade, assim como a existência de seletividade sobre em quais países intervir, o que pode ser considerado um dos mais graves problemas a serem enfrentados. Além da necessidade de adotar todas as dimensões possíveis, inclusive a reconstrução, para se alcançar o verdadeiro sentido do princípio. Mas não há como negar a importância do surgimento da R2P é algo notável, o que é preciso é o aprimoramento em sua aplicação.

De acordo com o relatório da ICISS, as organizações não-governamentais, nacionais e transnacionais têm também um importante papel, pressionando moralmente os Estados a protegerem seus cidadãos. Dentro desse contexto, no mundo atual, em que a globalização exerce forte influência na opinião pública, a mídia representa um forte aliado na mobilização da vontade política nacional e internacional, pois pode transmitir em tempo real imagens de violações de direitos humanos em diferente e longínquas portes do mundo, chamando a atenção de toda sociedade internacional (ICISS, 2001).

\section{CONSIDERAÇÕES FINAIS}

Desde o levante da primavera árabe que derrubou o ditador Muammar Kadhafi a disputa pelo poder, as instabilidades e os combates entre as milícias impediram a Líbia de se 
recuperar do caos no país. A Líbia permanece, até hoje, como palco de confrontos internos entre facções rivais e diferentes grupos armados. A atual crise migratória é fruto da instabilidade política e do vácuo de governança, que tem feito com que o país vivencie uma prolongada crise humanitária.

Diante da complexidade do assunto, é preciso que todos os Estados assumam suas responsabilidades, colaborando cada vez mais em um sentido de cooperação internacional e responsabilidade compartilhada, buscando uma reposta mais abrangente para o contexto atual de forma efetiva no país. A migração internacional é uma realidade multidimensional, assim é imprescindível que se desenvolva respostas coerentes e mais abrangentes diante do contexto atual e dos grandes desafios na proteção efetiva levando-se em conta os fatores e os resultados que tem gerado esse fenômeno crescente.

Nesse sentido, o presente artigo demonstrou o importante papel da sociedade internacional na situação atual da Líbia, principalmente no que concerne a atual crise migratória instalada no país. Ao cabo deste estudo, percebeu-se que a aplicação da responsabilidade de proteger no caso Líbio tem seus aspectos positivos, como fim da ditadura perpetrada no país por mais de 40 anos no Governo conhecido como "Era Qaddafi”. No entanto, a aplicação de tal princípio é criticado ao passo que a situação na Líbia não ficou resolvida com a intervenção e derrubada do Governo Qaddafi.

A ausência de uma das fases da aplicação do princípio, ou seja, a falta de reconstrução após a intervenção deixou a Líbia em uma situação crítica. Após o conflito de 2011, o país passou a ser palco de instabilidades políticas, sociais e econômicas. Inúmeros confrontos entre diversas milícias, as disputas pelo poder, o vácuo na governança e a atual crise migratória são alguns dos principais desafios a serem enfrentados pelo novo governo da Líbia que assumirá após as eleições de 2018. E porque não dizer que essa responsabilidade também é de toda comunidade internacional?

De acordo com o diálogo entre o Direito Internacional dos Direitos Humanos, Direito Internacional Humanitário e Direito Internacional dos Refugiados, a comunidade internacional exerce um papel fundamental de responsabilidade na proteção dos direitos humanos (CANÇADO TRINDADE, 2003). É importante lembrar que as autoridades da Líbia e todos os Estados-membros da ONU devem cumprir as normas internacionais no sentido de buscar a efetividade de proteção aos direitos humanos. 


\section{REFERÊNCIAS BIBLIOGRÁFICAS}

ACNUR. "Refugiados" e "Migrantes": Perguntas Frequentes. Disponível em: $<$ http://www.acnur.org/portugues/noticias/noticia/refugiados-e-migrantes-perguntasfrequentes/>. Acesso em: 28 jun. 2018.

ACNUR. 60 anos de ACNUR: Perspectivas de futuro. Disponível em:<http://www.acnur.org/t3/fileadmin/Documentos/portugues/Publicacoes/2011/60_anos_de _ACNUR_-_Perspectivas_de_futuro.pdf.> Acesso em: 20 jun. 2018.

ACNUR. Cúpula da ONU pretende "mudar de jogo" na proteção dos refugiados e migrantes. Disponível em: <http://www.acnur.org/portugues/noticias/noticia/cupula-da-onu-pretendemudar-o-jogo-na-protecao-de-refugiados-e-migrantes/>. Acesso em: 20 de junho de 2018.

ACNUR. Declaração de Nova York é 'uma oportunidade única' para refugiados, afirma chefe de proteção do ACNUR. Disponível <http://www.acnur.org/portugues/noticias/noticia/declaracao-de-nova-york-e-umaoportunidade-unica-para-refugiados-afirma-chefe-de-protecao-do-acnur $>$. Acesso em: 01 maio 2018.

ACNUR. Declaração de NY sobre migrantes e refugiados tem 'força política e ressonância sem precedentes', diz ACNUR. Disponível em: <https://nacoesunidas.org/declaracao-de-nysobre-migrantes-e-refugiados-tem-forca-politica-e-ressonancia-sem-precedentes-diz-acnur $>$. Acesso em 02 jun. 2018.

ACNUR. Missão do ACNUR. Disponível em: <http://www.acnur.org/portugues/informacaogeral/a-missao-do-acnur/> Acesso em: 02 jun. 2018.

ACNUR. Relatório anual "Tendências Globais" ("Global Trends") sobre refugiados e outras populações de interesse do ACNUR. Disponível em: <http://www.acnur.org/portugues/recursos/estatisticas/>. Acesso em: 02 jun. 2018.

ANDRADE, José H. Fischel. Direito internacional dos refugiados: evolução histórica (19211952). Rio de Janeiro: Renovar, 1996.

APPIO, Eduardo. Direito das minorias. São Paulo: Revista dos Tribunais, 2008.

CANÇADO TRINDADE, Antônio Augusto. A humanização do direito internacional. 2. ed. rev., atual. e ampl. Belo Horizonte: Del Rey, 2015.

CANÇADO TRINDADE, Antônio Augusto. Tratado de direito internacional dos direitos humanos. Porto Alegre: Sergio Antonio Fabris Editor, 2003, v. I. 
CANÇADO TRINDADE, Antônio Augusto. Tratado de direito internacional dos direitos humanos. Porto Alegre: Sergio Antonio Fabris Editor, 2003, v. III.

CANÇADO TRINDADE, Antônio Augusto; PEYTRIGNET, Gérard; SANTIAGO, Jaime Ruiz. Las tres vertientes de la proteccion internacional de los derechos de la persona humana. 1. ed. México: Editorial Porrúa, 2003.

CIA WORLD FACTBOOK. Libya 2011. Disponível em: <https://www.cia.gov/library/publications/the -world-factbook/geos/ly.html> Acesso em: 20 de junho de 2018

CUNHA, Mayara; STERNBERG,Sami; SOARES, Thaís; SANTOS, Victória. Responsabilidade de proteger: Avanços e desafios na implementação de um novo princípio para a proteção de indivíduos. Disponível em: <http://sinus.org.br/2012/wpcontent/uploads/06-AGNU.pdf>. Acesso em: 02 abr. 2018.

FEFERBAUM, Marina. Proteção internacional dos direitos humanos: análise do sistema africano. 1. ed. São Paulo: Saraiva 2012.

ICC. Statement to the United Nations Security Council on the Situation in Libya, pursuant to UNSCR $1970 \quad$ (2011). Disponível em: <https://www.icccpi.int/Pages/item.aspx?name=180509-otp-stat-UNSC-lib>. Acesso em: 10 maio 2018.

JAYME, Erick. Identité culturelle et intégration: le droit international privé postmoderne. Recueil des Cours, 1995, v.251.

JUBILUT, Liliana Lyra, APOLINÁRIO, Silvia Menicucce . O. S. A necessidade de proteção internacional no âmbito da migração. Disponível em: <https://www.academia.edu/25702193/A_necessidade_de_prote\%C3\%A7\%C3\%A3o_int ernacional_no_\%C3\%A2mbito_da_migra\%C3\%A7\%C3\%A3o>. Acesso em: 02 jun. 2018.

JUBILUT, Liliana Lyra. O direito internacional dos refugiados e sua aplicação no ordenamento jurídico brasileiro. São Paulo: Método, 2007.

JUBILUT, Liliana Lyra; MADUREIRA, André de Lima. Os desafios de proteção aos refugiados e migrantes forçados no marco de Cartagena +30 . Disponível em: <http://www.scielo.br/pdf/remhu/v22n43/v22n43a02.pdf>. Acesso em: 3 maio 2018.

JUBILUT, Liliana Lyra. Lidar com deslocamento em massa. Disponível em: $<$ https://nacoesunidas.org/cupula-sobre-refugio-e-migracao-vai-mudar-postura-dos-paisespara-lidar-com-deslocamento-em-massa/> . Acesso em: 03 jun. 2018. 
JUBILUT, Liliana Lyra. A "responsabilidade de proteger" é uma mudança real para intervenções humanitárias?

Disponível em: $<$ http://centrodireitointernacional.com.br/static/revistaeletronica/artigos/Liliana\%20Jubilut\%2 ODIH.pdf>. Acesso em: 02 abr. 2018.

MAZZUOLI, Valério de Oliveira. Curso de direito internacional público. 10. ed. rev., atual. e ampl. São Paulo: Revista dos Tribunais, 2016.

MAZZUOLI, Valério de Oliveira. Curso de direitos humanos. 3. ed. rev., atual. e ampl São Paulo: Método, 2016.

MSF. Acabem com a detenção arbitrária de refugiados, solicitantes de asilo e migrantes na Líbia. Disponível em: <https://www.msf.org.br/noticias/acabem-com-detencao-arbitraria-derefugiados-solicitantes-de-asilo-e-migrantes-na-libia>. Acesso em: 05 jun. 2018.

MSF. Líbia: dezenas de refugiados e migrantes feridos por traficantes que os sequestraram Disponível em: <https://www.msf.org.br/noticias/libia-dezenas-de-refugiados-e-migrantesferidos-por-traficantes-que-os-sequestraram>. Acesso em: 10 jun. 2018.

MSF. Líbia: MSF oferece cuidados de saúde a migrantes e refugiados detidos em Trípoli Disponível em: <https://www.msf.org.br/noticias/libia-msf-oferece-cuidados-de-saudemigrantes-e-refugiados-detidos-em-tripoli>. Acesso em: 11 jun. 2018.

MSF. Líbia: o tempo se esgota para os 800 migrantes e refugiados presos em centros de detenção. Disponível em: <https://www.msf.org.br/noticias/libia-o-tempo-se-esgota-para-os800-migrantes-e-refugiados-presos-em-centros-de-detencao>. Acesso em: 11 jun. 2018.

MSF. Líbia: oferecendo assistência a migrantes e refugiados. Disponível: <https://www.msf.org.br/noticias/libia-oferecendo-assistencia-migrantes-e-refugiados>. Acesso em: 10 jun. 2018.

ONU. Conselho de Segurança condena tráfico migrantes escravizados na Líbia. Disponível em: <nacoesunidas.org/conselho-de-seguranca-condena-trafico-migrantes-escravizados-nalibia/>. Acesso em: 20 jun. 2018.

ONU. Declaração de Nova York sobre refugiados e migrantes. Disponível em: $<$ http://www.un.org/en/ga/search/view_doc.asp?symbol=A/RES/71/1>. Acesso em: 25 maio 2018.

ONU. Número crescente de conflitos mostra que prevenção é mais necessária do que nunca, diz Guterres. Disponível em: <nacoesunidas.org/numero-crescente-de-conflitos-mostra-queprevencao-e-mais-necessaria-do-que-nunca-diz-guterres/>. Acesso em: 27 jun. 2018. 
ONU. Número de migrantes internacionais chega a cerca de 244 milhões, revela ONU. Disponível em: <https://nacoesunidas.org/numero-de-migrantes-internacionais-chega-a-cercade-244-milhoes-revela-onu/>. Acesso em: 02 jun. 2018.

ONU. ONU evacuou mais de mil refugiados da Líbia desde novembro de 2017. Disponível em: <https://nacoesunidas.org/onu-evacuou-mais-de-mil-refugiados-da-libia-desdenovembro-de-2017/>. Acesso em: 04 jun. 2018.

ONU. ONU intensifica trabalho para proteger refugiados e migrantes do tráfico humano no Mediterrâneo. Disponível em: <https://nacoesunidas.org/onu-intensifica-trabalho-paraproteger-refugiados-e-migrantes-do-trafico-humano-no-mediterraneo/>. Acesso em: 04 jun. 2018.

ONU. ONU pede US\$ 313 mil para levar assistência a 940 mil pessoas na Líbia. Disponível em: <https://nacoesunidas.org/onu-pede-us-313-mi-para-levar-assistencia-a-940-mil-pessoasna-libia/>. Acesso em: 02 maio 2018.

ONU. Organização internacional para as migrações fortalece vínculos com a ONU. Disponível em: https://nacoesunidas.org/organizacao-internacional-para-as-migracoesfortalece-vinculos-com-onu/. Acesso em: 03 jun. 2018.

ONU. Proteger refugiados na Líbia é 'trabalho mais desafiador que já tive', diz representante da ONU. Disponível em: <https://nacoesunidas.org/proteger-refugiados-na-libia-e-trabalhomais-desafiador-que-ja-tive-diz-representante-da-onu/>. Acesso em: 05 jun. 2018.

ONU. Refugiados e migrantes são vítimas de trabalho forçado e cárcere em rotas que levam à Líbia. Disponível em: <https://nacoesunidas.org/refugiados-e-migrantes-sao-vitimas-detrabalho-forcado-e-carcere-em-rotas-que-levam-a-libia/>. Acesso em: 05 jun. 2018.

ONU. Relatores da ONU pedem fim de leilão de migrantes africanos na Líbia. Disponível em: <https://nacoesunidas.org/relatores-da-onu-pedem-fim-de-leilao-de-migrantes-africanosna-libia/>. Acesso em: 04 jun. 2018.

ONU. Líbia: ONU pede que partes em conflito coloquem país à frente de 'interesses estreitos'. Disponível em: <https://nacoesunidas.org/libia-onu-pede-que-partes-em-conflitocoloquem-pais-a-frente-de-interesses-estreitos/> . Acesso em: 02 maio 2018.

ONU. Conflitos na Líbia provocam crise humanitária e deixam dezenas de pessoas mortas, diz ONU. Disponível em: <https://nacoesunidas.org/conflitos-na-libia-provocam-crisehumanitaria-e-deixam-dezenas-de-pessoas-mortas-diz-onu/> Acesso em: 02 maio 2018. 
ONU. Líbia sofre com ameaça de novo conflito; enviado da ONU pede contenção. Disponível em: <https://nacoesunidas.org/libia-sofre-com-ameaca-de-novo-conflito-enviado-da-onupede-contencao/>. Acesso em: 02 maio 2018.

ONU. Com 435 mil pessoas deslocadas, situação na Líbia é 'trágica', alerta ONU. Disponível em: <https://nacoesunidas.org/com-435-mil-pessoas-deslocadas-situacao-na-libia-e-tragicaalerta-onu/>. Acesso em: 02 maio 2018.

PIOVESAN, Flávia. Direitos humanos e o direito constitucional internacional. 16. ed., rev., ampl. e atual., São Paulo: Saraiva 2016.

Submetido em: 17/10/2018

Aceito em: 18/02/2019 